\title{
Examining older patient preferences for quality of care in postacute transition care and day rehabilitation programs
}

\author{
Leah Couzner $^{1^{*}}$, Maria Crotty ${ }^{1}$, Ruth Walker ${ }^{2}$, Julie Ratcliffe ${ }^{3}$ \\ ${ }^{1}$ Department of Rehabilitation, Aged and Extended Care, Flinders University, Adelaide, Australia; \\ *Corresponding Author: leah.couzner@,flinders.edu.au \\ ${ }^{2}$ South Australian Community Health Research Unit, Flinders University, Adelaide, Australia \\ ${ }^{3}$ Flinders Clinical Effectiveness, Flinders University, Adelaide, Australia
}

Received 17 April 2013; revised 18 May 2013; accepted 10 June 2013

Copyright (C) 2013 Leah Couzner et al. This is an open access article distributed under the Creative Commons Attribution License, which permits unrestricted use, distribution, and reproduction in any medium, provided the original work is properly cited.

\begin{abstract}
Background: Quality in health care has traditionally been determined based on clinical or health outcomes. However, these factors may not be the only aspects of health care that are important to patients. Within rehabilitation factors related to the process of care, the way in which rehabilitation services are delivered, may also be important to patients when defining quality of care. Objective: The purpose of this study was to examine and compare the preferences of older people receiving post-acute outpatient rehabilitation or residential intermediate (transition) care for alternative configurations of rehabilitation programs. Methods: A discrete choice experiment (DCE) was designed to elicit the preferences of older people for the design and delivery of post-acute rehabilitation programs. The participants were older adults ( $\geq 65$ years) receiving post-acute outpatient rehabilitation or residential intermediate (transition) care in South Australia. Each participant was presented with a series of choice questions involving two hypothetical programs, the characteristics of which varied in every choice. Participants were then asked to select their preferred program. Results: Despite marked differences in case-mix and dependency levels, the preferences of the two groups were very similar, focusing on relationships and communication with health care professionals. Both groups demonstrated very strong preferences for the use of an electronic medical record and for receiving information about their treatment and
\end{abstract}

progress via a meeting with a specialist physician and nurse. The outpatient rehabilitation group also exhibited a strong preference for a shared decision making model in relation to their future care needs. Conclusions: The findings highlight the commonality of preferences of older patients receiving post-acute services for the optimal configuration of rehabilitation services. Issues prioritised were service integration and access to senior medical and nursing staff. The study demonstrates the practicality and validity of DCEs to determine older people's preferences in defining quality of care.

Keywords: DCE; Patient Preferences; Aged; Rehabilitation; Intermediate Care Facilities

\section{INTRODUCTION}

Quality in health care has been traditionally based upon the views of health professionals and largely focused upon the measurement of clinical and health outcomes of patients [1]. The disadvantage of this approach lies in the possibility that the factors which are considered as most important to health professionals may not be the factors which are most important to patients themselves. Health outcomes may not be the only aspect of health care of importance to older people and their families $[1,2]$. The process of receiving health care, for example waiting time, continuity of care, or treatment type may also be a highly important indicator of quality of care [3-6].

To date, the quality of health care from the patient's perspective has typically been measured using methods such as patient satisfaction surveys. However, several 
studies using patient satisfaction surveys have found older people are more likely than younger participants to give socially-desirable responses, are less inclined to complain and more likely to express gratitude [7,8]. A systematic review by Crow and colleagues on patient satisfaction revealed that older people are generally more likely to agree with questions worded in a positive way, thereby bringing the accuracy of their responses into question, and also more likely to report high levels of satisfaction, potentially due to lower expectations of health care $[8,9]$.

Given the predicted increase in life expectancy, subsequent ageing population and increased demand on health and social care services, it is important for preference elicitation techniques to be available that are suitable for use with older adults. A preference elicitation method that is becoming more commonly utilised within the health care sector is the discrete choice experiment (DCE). This approach defines health care interventions or services in terms of their key characteristics or attributes and their associated levels. Within a DCE, respondents are presented with a series of hypothetical scenarios describing different health care interventions from which they are asked to indicate their preferences. Each scenario is described in terms of its characteristics (attributes) which consist of varying levels. For example an attribute of "chance of complete recovery" may have corresponding levels of $50 \%, 75 \%$ and $100 \%$. It is assumed that respondents will make trade-offs between the attributes in order to choose their preferred scenario. Their final choices can then be analysed to interpret the influence of each attribute on their overall decision [10]. The overall utility or benefit that would be gained from alternative scenarios can also be determined. An additional advantage of DCEs is that they enable the relative importance of multiple aspects of health care to be assessed simultaneously. Thus DCEs may include healthrelated outcomes such as mortality rate, non-health related outcomes including cost of treatment, or elements of health care process such as type of treatment, or a combination of these elements.

Despite their increasing prevalence and widespread utilisation in the health care sector, DCEs have rarely been utilised in rehabilitation medicine with populations of older people $[2,11,12]$. Previous work has suggested that patients' current state of health may influence their assessment of quality of care and what components of care are important $[5,13]$. Therefore, we hypothesised that depending on the stage of recovery, older people in post-acute care programs would prioritise different issues. For example those in day rehabilitation who had recovered well enough to go home and return for outpatient treatment might have a higher interest in the approach to therapy delivery than in factors relating to medical man- agement and service integration. Once identified these differences might allow changes in service models. The main aim of this study was to examine and compare the preferences of older people currently receiving either outpatient rehabilitation or transition care following an acute event for alternative configurations of rehabilitation programs.

\section{METHOD}

\subsection{Scenario Development/Experiment Design}

The selection and description of the key attributes and levels was developed via consultation with a panel of clinicians, a literature review and a series of qualitative interviews $(n=20)$ with older rehabilitation patients (aged 65 years and over) to ascertain the aspects of post-acute rehabilitation of importance to patients following an acute hospital stay. Five attributes were developed, each consisting of 3 levels as shown in Table 1. This resulted in 243 possible scenarios for presentation in the form of hypothetical rehabilitation programs with varying attribute levels. This was reduced to a more manageable number for the purposes of valuation using a fractional factorial design and the techniques described in Street and Burgess [14] resulting in 18 binary choice sets which were $100 \%$ efficient for estimating the main effects. The 18 binary choice sets were divided into 4 blocks or versions, 2 of which contained 4 choice sets and 2 consisting of 5 choice sets to reduce the cognitive burden upon respondents. An example of a choice set is presented in Table 2.

Prior to the main DCE study, a small pilot study was conducted with older people receiving outpatient rehabilitation $(n=20)$, firstly to check the realism and relevance of the attributes and levels presented from the participants' perspective and secondly to check understanding and completion rates. A within-experiment reliability test was also included within the experiment, whereby participants were presented with the same choice set twice, once near to the beginning of the DCE task and then again at the end.

\subsection{Data Collection}

Participants were recruited from an outpatient day rehabilitation program at the Repatriation General Hospital, a 300 bed acute care hospital in metropolitan Adelaide, South Australia, and a residential post-acute intermediate care (transition care) facility providing rehabilitation type care to people aged 65 and over. These two groups were selected as they represent differing levels of independence and forms of post-acute care after being discharged from an acute health care setting. Inclusion cri- 
Table 1. DCE attributes and levels.

\begin{tabular}{|c|c|}
\hline Attributes & Levels \\
\hline \multirow{3}{*}{$\begin{array}{l}\text { Family and patient } \\
\text { involvement in the } \\
\text { decision to move } \\
\text { from hospital to the } \\
\text { next destination e.g. } \\
\text { returning home, moving } \\
\text { to a nursing home }\end{array}$} & $\begin{array}{l}\text { Clinicians make the decision and the family } \\
\text { and patient are informed afterwards }\end{array}$ \\
\hline & Shared decision making with clinicians \\
\hline & $\begin{array}{l}\text { The family and patient make their own } \\
\text { decision to move without any involvement } \\
\text { from the clinicians }\end{array}$ \\
\hline \multirow{3}{*}{$\begin{array}{l}\text { How the patient's } \\
\text { medical history is } \\
\text { transferred between } \\
\text { the health care } \\
\text { professionals who } \\
\text { are caring for them }\end{array}$} & No record is received about the patient \\
\hline & $\begin{array}{l}\text { A written summary of the patient's condition } \\
\text { and current medications is received within } \\
\text { one week of the patient being transferred }\end{array}$ \\
\hline & $\begin{array}{l}\text { A full electronic record of the patient's health } \\
\text { background, previous health care usage and } \\
\text { past and current medications is automatically } \\
\text { transferred with the patient }\end{array}$ \\
\hline \multirow{3}{*}{$\begin{array}{l}\text { Intensity of } \\
\text { rehabilitation } \\
\text { programme }\end{array}$} & $\begin{array}{l}\text { Once weekly group therapy delivered by a } \\
\text { physiotherapist }\end{array}$ \\
\hline & $\begin{array}{c}\text { Twice weekly individual physiotherapy and } \\
\text { occupational therapy delivered by skilled } \\
\text { health care professionals }\end{array}$ \\
\hline & $\begin{array}{c}\text { Daily individual physiotherapy and } \\
\text { occupational therapy delivered by skilled } \\
\text { health care professionals }\end{array}$ \\
\hline \multirow{3}{*}{$\begin{array}{l}\text { How the patient will } \\
\text { get information about } \\
\text { their health and } \\
\text { treatment whilst } \\
\text { receiving care }\end{array}$} & $\begin{array}{l}\text { Patient will get information from health care } \\
\text { professionals if they ask them. }\end{array}$ \\
\hline & $\begin{array}{c}\text { A meeting for the patient and a family } \\
\text { member with a social worker and junior } \\
\text { doctor }\end{array}$ \\
\hline & $\begin{array}{l}\text { A meeting between the patient and a family } \\
\text { member with a senior doctor and specialist } \\
\text { aged care nurse with take home written } \\
\text { summary and audio recording, and follow up } \\
\text { meeting and phone call from the nurse }\end{array}$ \\
\hline \multirow{3}{*}{$\begin{array}{l}\text { Duration of } \\
\text { rehabilitation } \\
\text { therapy provided }\end{array}$} & A set period of 2 weeks \\
\hline & Decided by medical team \\
\hline & Until the patient thinks they are well \\
\hline
\end{tabular}

Teria were: aged $\geq 65$ years, Mini Mental Sate Examination (MMSE) score of $\geq 24$ [16], receiving outpatient day rehabilitation or residential intermediate (transition) care following an acute hospital admission; absence of communication or comprehension difficulties, e.g. dysphasia or non-English speaking background as determined by the treating health care team.

The participants completed the questionnaire via a face-to-face interview approximately 4 weeks after commencing rehabilitation or transition care. The questionnaire contained 3 sections. Section A comprised a series of attitudinal statements regarding rehabilitations services and health care for older people. The statements were accompanied by a likert-type scale in which participants indicated the level to which they agreed or disagreed with each statement. Section B contained the DCE task. Section C included measures of self-reported health status, the quality of transition between health
Table 2. Example choice set.

\begin{tabular}{|c|c|c|}
\hline & Program A & Program B \\
\hline $\begin{array}{l}\text { Patient \& family involvement in } \\
\text { the decision to move from } \\
\text { hospital to the next destination }\end{array}$ & None & Shared \\
\hline $\begin{array}{l}\text { How your medical history } \\
\text { is transferred between the } \\
\text { health care professionals who } \\
\text { are caring for you }\end{array}$ & $\begin{array}{l}\text { Full electronic } \\
\text { record }\end{array}$ & A written record \\
\hline $\begin{array}{l}\text { Intensity of rehabilitation } \\
\text { programme }\end{array}$ & $\begin{array}{l}\text { Twice weekly } \\
\text { therapy }\end{array}$ & Daily therapy \\
\hline $\begin{array}{l}\text { How you will get information } \\
\text { about your health and } \\
\text { treatment whilst receiving care }\end{array}$ & $\begin{array}{l}\text { Senior doctor and } \\
\text { specialist aged care } \\
\text { nurse with follow } \\
\text { up and summary }\end{array}$ & $\begin{array}{l}\text { Social worker } \\
\text { and junior } \\
\text { doctor }\end{array}$ \\
\hline $\begin{array}{l}\text { Duration of rehabilitation } \\
\text { therapy provided }\end{array}$ & Decided by team & $\begin{array}{l}\text { Until you think } \\
\text { you are well }\end{array}$ \\
\hline
\end{tabular}

settings and a series of socio-demographic questions.

\subsection{Data Analysis}

A random effects regression model within the software package STATA version 11 [16] was estimated to analyse the influence of the 5 attributes on participants' choices whereby the scenario chosen by the participant, hypothetical program A or B, was the binary dependent variable and the levels of each attribute were the explanatory variables. The attribute levels were dummy coded [17] and the base levels were excluded from the regression model. Statistical significance of the coefficient attached to a particular attribute level indicates the relative importance of the attribute level in influencing participants' choices. A positive coefficient indicates that the attribute level was associated with increased utility, whilst a negative coefficient indicates that the attribute level was associated with a reduction in utility.

Participants may exhibit dominant preferences when completing DCEs in which they appear to make choices between scenarios based upon a single attribute alone rather than trading between all the of attribute levels presented. As these responses are not necessarily invalid, excluding them may result in sample selection bias and statistical inefficiency [18]. For this reason, participants who displayed dominant preferences were identified, but not excluded from the analysis. Participants who did not pass the within-experiment reliability test were excluded from the analysis.

Approval to conduct the study was obtained from the Southern Adelaide Health Service/Flinders University Human Research Ethics Committee.

\section{RESULTS}

A total of 80 participants completed the DCE task. The participants had a mean age of 76.94 years (SD 0.86), 
with the intermediate (transition) care group being slightly older than the outpatient day rehabilitation group [mean age 80.30 (range 65 - 89) and 74.79 (range 66 - 92) respectively]. At the time of interview, the intermediate (transition) care recipients had been receiving post-acute care for a longer duration than the outpatient rehabilitation recipients [mean days 41.15 (SD 20.78) and 33.88 (SD 16.58) respectively]. The most common reason for receiving post-acute care for the intermediate (transition) care group was orthopaedic diagnoses such as fractures ( $n$ $=15,56 \%$ ), while neurological diagnoses such as stroke were the most common reason for the outpatient rehabilitation group $(n=24,57 \%)$. Eleven $(14 \%)$ participants failed the within experiment reliability test and were therefore excluded from the DCE data analysis giving a total of 69 participants included (outpatient rehabilitation $n=42$; intermediate care $n=27$ ). The demographics of the included participants are presented in Table 3.

The results of the random effects regression models are presented in Table 4. Both the intermediate (transition) care and day rehabilitation groups demonstrated very strong preferences for the transfer of a full electronic medical record between health professionals caring for an older person (coefficient $0.93, \mathrm{p} \leq 0.001$ and coefficient $0.79, \mathrm{p} \leq 0.001$ respectively). Very strong preferences were also shown by both groups for the medical team determining the duration of rehabilitation therapy (transition care coefficient $0.63, \mathrm{p} \leq 0.001$; rehabilitation coefficient $0.80, \mathrm{p} \leq 0.001$ ).

Both groups displayed a strong preference for older people to receive information about their treatment and progress via a meeting with senior specialist staff (medical and nursing) with follow-up and a take-home audio recording of the meeting the most preferred level. The intermediate (transition) care recipients demonstrated a stronger preference for this particular attribute level than the rehabilitation group (coefficient 1.03, $p=0.01$ and coefficient $0.62, p=0.01$ respectively). Additionally, the outpatient day rehabilitation group exhibited a very strong preference for shared decision making, with medical staff regarding the post-acute discharge destination (coefficient $0.89, p \leq 0.001)$. The majority of participants $(n=44$, $64 \%$ ) displayed non-dominant preferences as shown in Table 5, suggesting that most participants were trading

Table 3. Participant characteristics.

\begin{tabular}{|c|c|c|c|}
\hline Characteristic & $\begin{array}{c}\text { Outpatient rehabilitation } \\
\text { patients } n=42\end{array}$ & $\begin{array}{c}\text { Residential transition care } \\
\text { patients } n=27\end{array}$ & $\begin{array}{c}\text { All participants } \\
n=69\end{array}$ \\
\hline Age (mean years, sd) & $74.79(6.63)$ & $80.30(6.59)$ & 76.94 \\
\hline Cognition (mean MMSE score, sd) & $28.17(1.81)$ & $28.11(1.58)$ & 28 \\
\hline Post-acute care duration (mean days, sd) & $33.88(16.58)$ & $41.15(20.78)$ & 37 \\
\hline EQ-5D score (mean, sd) & $0.52(0.24)$ & $0.53(0.28)$ & $0.52(0.26)$ \\
\hline \multicolumn{4}{|l|}{ Gender } \\
\hline Male & $20(48 \%)$ & $11(41 \%)$ & $31(45)$ \\
\hline Female & $22(52 \%)$ & $16(59 \%)$ & $38(55)$ \\
\hline \multicolumn{4}{|l|}{ Has an informal carer } \\
\hline Yes & $28(67 \%)$ & $19(70 \%)$ & $47(68)$ \\
\hline No & $14(33 \%)$ & $8(30 \%)$ & $22(32)$ \\
\hline \multicolumn{4}{|l|}{ Residential Status } \\
\hline Living alone & $10(24 \%)$ & $19(70 \%)$ & $29(42)$ \\
\hline Living with others & $32(76 \%)$ & $8(30 \%)$ & $40(58)$ \\
\hline \multicolumn{4}{|l|}{ Country of Birth } \\
\hline Australia & $32(76 \%)$ & $22(81 \%)$ & $54(78)$ \\
\hline Other & $10(24 \%)$ & $5(19 \%)$ & $15(22)$ \\
\hline \multicolumn{4}{|l|}{ Highest Education } \\
\hline Primary or secondary & $21(50 \%)$ & $18(72 \%)$ & $39(58)$ \\
\hline Tertiary & $21(50 \%)$ & $7(28 \%)$ & $28(42)$ \\
\hline \multicolumn{4}{|l|}{ Reason for post-acute care (\%) } \\
\hline Neurological & $24(57 \%)$ & $1(4 \%)$ & $27(39)$ \\
\hline Orthopaedic & $7(17 \%)$ & $15(56 \%)$ & $24(35)$ \\
\hline Functional decline/falls/mobility & $7(17 \%)$ & $7(26 \%)$ & $14(20)$ \\
\hline Other & $4(10 \%)$ & $4(15 \%)$ & $4(5)$ \\
\hline
\end{tabular}


Table 4. Results of random effects probit regression model (DCE) by therapy group.

\begin{tabular}{|c|c|c|c|c|c|c|}
\hline \multirow{2}{*}{ Attribute } & \multicolumn{3}{|c|}{ Outpatient Rehabilitation $(n=42)$} & \multicolumn{3}{|c|}{ Residential Transition Care $(n=27)$} \\
\hline & Coefficient & Standard Error & $p$ Value & Coefficient & Standard Error & $p$ Value \\
\hline Shared $^{* *}$ & 0.89 & 0.24 & $\leq 0.001$ & 0.40 & 0.30 & 0.19 \\
\hline Total & 0.36 & 0.20 & 0.08 & 0.32 & 0.26 & 0.22 \\
\hline Written $^{\dagger}$ & 0.33 & 0.19 & 0.07 & 0.59 & 0.23 & 0.01 \\
\hline Full $^{* *, \dagger}$ & 0.79 & 0.19 & $\leq 0.001$ & 0.93 & 0.29 & $\leq 0.001$ \\
\hline Twice & 0.18 & 0.19 & 0.35 & 0.01 & 0.24 & 0.99 \\
\hline Daily $^{\dagger}$ & 0.18 & 0.18 & 0.30 & 0.67 & 0.28 & 0.02 \\
\hline Junior & 0.19 & 0.20 & 0.39 & 0.28 & 0.23 & 0.22 \\
\hline Specialist $^{* \dagger}$ & 0.62 & 0.25 & 0.01 & 1.03 & 0.37 & 0.01 \\
\hline Team $^{* *, \dagger \dagger}$ & 0.80 & 0.19 & $\leq 0.001$ & 0.63 & 0.20 & $\leq 0.001$ \\
\hline You $^{*, \dagger}$ & 0.50 & 0.19 & 0.01 & 0.55 & 0.23 & 0.02 \\
\hline
\end{tabular}

Number of obs $=189 \quad$ Number of obs $=122$

Number of groups $=42 \quad$ Number of groups $=27$

Wald Chi2 $(10)=36.09 \quad$ Wald Chi2 $(10)=26.21$

Log likelihood $=-94.22 \quad$ Log likelihood $=-58.48$

*Significant at the $5 \%$ level for outpatient rehabilitation group; ${ }^{* *}$ Significant at the $1 \%$ level for outpatient rehabilitation group; ${ }^{\dagger}$ Significant at the $5 \%$ level for residential transition care group; ${ }^{\dagger \dagger}$ Significant at the $1 \%$ level for residential transition care group.

Table 5. Dominant preferences for attributes.

\begin{tabular}{cccc}
\hline \multirow{2}{*}{ Attribute } & \multicolumn{3}{c}{ Participants (n, \%) } \\
\cline { 2 - 4 } & $\begin{array}{c}\text { Rehabilitation } \\
\boldsymbol{n}=\mathbf{4 2}\end{array}$ & $\begin{array}{c}\text { Transition Care } \\
\boldsymbol{n}=\mathbf{2 7}\end{array}$ & $\begin{array}{c}\text { Total } \\
\boldsymbol{n}=\mathbf{6 9}\end{array}$ \\
\hline Involvement & $1(2)$ & - & $1(1)$ \\
History & $5(12)$ & $5(19)$ & $10(14)$ \\
Intensity & $4(10)$ & - & $4(5)$ \\
Information & - & $3(11)$ & $3(4)$ \\
Duration & $3(7)$ & $4(15)$ & $7(10)$ \\
No dominance & $29(69)$ & $15(56)$ & $44(64)$ \\
\hline
\end{tabular}

between all the attributes rather than making choices based on one or more particular attribute. However, the intermediate (transition) care recipients were more likely than the outpatient day rehabilitation recipients to exhibit dominant preferences $(n=12,44 \%$ and $n=13,31 \%$ respectively). The attribute most commonly associated with dominance for both groups was the use of an electronic medical record to transfer patients' medical history between the staff caring for them at different sites (rehabilitation: $n=5,12 \%$; transition care: $n=5,19 \%$ ).

The responses to the attitudinal statements are presented in Table 6. The outpatient day rehabilitation recipients were more likely than the intermediate (transition) care recipients to strongly agree that older people should be involved in decisions about their own future care wherever possible ( $n=28,67 \%$ vs. $n=12,44 \%$ ). A greater percentage of the day rehabilitation group also strongly agreed that an intensive rehabilitation programme can make a substantial difference to older people's functioning and quality of life $(n=26,62 \%$ vs. $n=$
$11,41 \%)$. The responses of the rehabilitation group were found to be very similar to those of the intermediate (transition) care group for all of the remaining attitudinal statements.

\section{DISCUSSION}

This pilot study aimed to examine and compare the preferences of older people receiving either outpatient day rehabilitation or residential intermediate (transition) care following an acute event for alternative configurations of rehabilitation programs. Although the two patient groups differed in terms of their clinical characteristics, the elements of service provision that define quality of health care proved to be very similar for both groups. The high rates of completion and participants' understanding provides support for the practicality and face validity of the DCE approach in an older population. The preferences demonstrated in the DCE results also generally corresponded with the opinions expressed in the attitudinal statements demonstrating a high degree of convergent validity. Both groups prioritised continuity of care and communication as a key feature of high quality post-acute care which is consistent with UK reports on the hospital experiences of older adults with multiple health problems [19].

The only marked difference between groups related to shared decision making, with the outpatient rehabilitation recipients expressing much stronger preferences overall to be involved in decisions about their own future care. A possible explanation for this may be that the rehabilitation group were further along their recovery trajectory and may have felt more confident in participating in de- 
Table 6. Dominant preferences for attributes.

\begin{tabular}{|c|c|c|c|c|c|c|c|c|c|c|}
\hline & \multicolumn{5}{|c|}{ Outpatient Rehabilitation $(n=42)$} & \multicolumn{5}{|c|}{ Transition Care $(n=27)$} \\
\hline & $\begin{array}{l}\text { Strongly } \\
\text { agree } \\
n(\%)\end{array}$ & $\begin{array}{l}\text { Agree } \\
n(\%)\end{array}$ & $\begin{array}{c}\text { Neither agree } \\
\text { nor disagree } \\
n(\%)\end{array}$ & $\begin{array}{c}\text { Disagree } \\
n(\%)\end{array}$ & $\begin{array}{l}\text { Strongly } \\
\text { disagree } \\
n(\%)\end{array}$ & $\begin{array}{l}\text { Strongly } \\
\text { agree } \\
n(\%)\end{array}$ & $\begin{array}{l}\text { Agree } \\
n(\%)\end{array}$ & $\begin{array}{c}\text { Neither agree } \\
\text { nor disagree } \\
n(\%)\end{array}$ & $\begin{array}{c}\text { Disagree } \\
n(\%)\end{array}$ & $\begin{array}{l}\text { Strongly } \\
\text { disagree } \\
n(\%)\end{array}$ \\
\hline $\begin{array}{l}\text { Older people should be involved in } \\
\text { decisions about their own future care } \\
\text { wherever possible }\end{array}$ & $28(67 \%)$ & $\begin{array}{c}14 \\
(33 \%)\end{array}$ & - & - & - & $12(44 \%)$ & $\begin{array}{c}14 \\
(52 \%)\end{array}$ & $1(4 \%)$ & - & - \\
\hline $\begin{array}{l}\text { An intensive rehabilitation } \\
\text { programme can make a substantial } \\
\text { difference to older people's } \\
\text { functioning and quality of life }\end{array}$ & $26(62 \%)$ & $\begin{array}{c}14 \\
(33 \%)\end{array}$ & $2(5 \%)$ & - & - & $11(41 \%)$ & $\begin{array}{c}14 \\
(52 \%)\end{array}$ & $2(7 \%)$ & - & - \\
\hline $\begin{array}{l}\text { The immediate family (rather than } \\
\text { the older person) is best placed to make } \\
\text { decisions about the older } \\
\text { person's future care }\end{array}$ & $5(12 \%)$ & $\begin{array}{c}15 \\
(36 \%)\end{array}$ & $6(14 \%)$ & $16(38 \%)$ & - & $4(15 \%)$ & $\begin{array}{c}7 \\
(26 \%)\end{array}$ & $7(26 \%)$ & $7(26 \%)$ & $2(7 \%)$ \\
\hline $\begin{array}{l}\text { The development of self confidence } \\
\text { is a key ingredient in improving } \\
\text { older people's functioning }\end{array}$ & $21(50 \%)$ & $\begin{array}{c}20 \\
(48 \%)\end{array}$ & $1(2 \%)$ & - & - & $11(41 \%)$ & $\begin{array}{c}14 \\
(52 \%)\end{array}$ & $2(7 \%)$ & - & - \\
\hline $\begin{array}{l}\text { The communication between health } \\
\text { care professionals in different } \\
\text { settings is poor (e.g. between } \\
\text { hospitals and nursing homes or GPs) }\end{array}$ & $7(17 \%)$ & $\begin{array}{c}7 \\
(17 \%)\end{array}$ & $11(26 \%)$ & $14(33 \%)$ & $3(7 \%)$ & - & $\begin{array}{c}11 \\
(41 \%)\end{array}$ & $8(30 \%)$ & $8(30 \%)$ & - \\
\hline $\begin{array}{l}\text { The communication between health } \\
\text { care professionals and the older } \\
\text { person and their family is poor }\end{array}$ & $3(7 \%)$ & $\begin{array}{c}4 \\
(10 \%)\end{array}$ & $5(12 \%)$ & $27(64 \%)$ & $3(7 \%)$ & $2(7 \%)$ & $\begin{array}{c}4 \\
(15 \%)\end{array}$ & $2(7 \%)$ & $16(59 \%)$ & $2(7 \%)$ \\
\hline $\begin{array}{l}\text { The health care services an older } \\
\text { person requires should be made } \\
\text { available to them regardless of } \\
\text { the costs to the health service }\end{array}$ & $12(29 \%)$ & $\begin{array}{c}22 \\
(52 \%)\end{array}$ & $5(12 \%)$ & $3(7 \%)$ & - & $10(37 \%)$ & $\begin{array}{c}12 \\
(44 \%)\end{array}$ & $1(4 \%)$ & $3(11 \%)$ & $1(4 \%)$ \\
\hline $\begin{array}{l}\text { Currently there aren't enough } \\
\text { rehabilitation services available for } \\
\text { the older people who need them }\end{array}$ & $7(17 \%)$ & $\begin{array}{c}14 \\
(33 \%)\end{array}$ & $11(26 \%)$ & $10(24 \%)$ & - & $6(22 \%)$ & $\begin{array}{c}11 \\
(41 \%)\end{array}$ & $8(30 \%)$ & $2(7 \%)$ & - \\
\hline $\begin{array}{l}\text { Currently there aren't enough } \\
\text { nursing home beds for the older } \\
\text { people who need them }\end{array}$ & $11(26 \%)$ & $\begin{array}{c}19 \\
(45 \%)\end{array}$ & $10(24 \%)$ & $2(5 \%)$ & - & $7(26 \%)$ & $\begin{array}{c}11 \\
(41 \%)\end{array}$ & $9(33 \%)$ & - & - \\
\hline
\end{tabular}

cisions regarding their future care. A previous study into autonomy in older rehabilitation patients in an acute care setting demonstrated that, as their recovery progressed; older acute health care recipients began to exert more independence and control and tended to participate more fully in decisions regarding their own health care [20].

Previous studies have suggested that communication with health providers and the provision of information are two key basic principles for defining quality health care, with the ability to motivate patients and positively influence their recovery [21,22]. This includes health professionals spending additional time with patients, giving them an opportunity to speak honestly and the provision of written information which can also be shared with the patient's family [23]. The findings from this study concur with this viewpoint; in general, participants exhibited strong preferences for communication with health providers and the provision of information.

Very strong preferences were also shown in both groups for the use of electronic medical records, suggesting the importance of communication between health care professionals. An electronic record was not available in South Australia in either hospital or post acute care settings at the time of the study yet. Although both groups had no exposure to the approach, it was felt to be important. However with the Australian government planning to introduce a personally controlled electronic health record system in mid-2012 [24], participants may have had some exposure to this concept via the media. The importance of inter-professional communication was also noted by Westby during focus groups conducted with rehabilitation patients, which revealed that poor communication between health care settings may negatively impact on patient satisfaction, clinical outcomes, and service coordination [25]. Eldar has also identified the interaction between multidisciplinary professionals as a potential influence on quality of care [6].

It is important to note that this study was essentially 
exploratory in nature and was necessarily conducted on a very modest research budget with a relatively small sample size. Hence the findings from this study should be interpreted with caution. However, our study has provided important preliminary evidence demonstrating the practicality and validity of the application of DCE methodology to determine older people's preferences regarding what constitutes quality in the delivery of health programs. It is important that further DCE studies are conducted in larger samples of older people to substantiate the findings from this study and to provide further evidence of the practicality and validity of this approach for application with older people.

Given the ageing of the population and the predicted future increase in the demand for health care both in Australia and internationally, involving older people in research which incorporates their views and preferences relating to the optimal configuration of health services is an increasingly important issue [26]. Future research is required into the application of DCEs with larger and more diverse samples of older people in different health and aged care settings to gain a deeper understanding of their preferences for quality care. The potential also exists for the future incorporation of DCEs into an economic evaluation framework, for assessing the cost effectiveness of health care interventions and services targeted for older people.

\section{FUNDING ACKNOWLEDGEMENTS}

This study was supported by a Flinders University Research Scholarship; and a National Health and Medical Research Council Health Services Research strategic award grant [grant number 402791].

\section{REFERENCES}

[1] Brown, C.R. (2007) Where are the patients in the quality of health care? International Journal for Quality in Health Care, 19, 125-126. doi:10.1093/intqhe/mzm009

[2] Ratcliffe, J., Laver, K., Couzner, L., Cameron, I., Gray, L. and Crotty, M. (2010) Not just about costs: The role of health economics in facilitating decision making in aged care, Age Ageing, 39, 426-429. doi:10.1093/ageing/afq041

[3] Mainz, J. (2003) Defining and classifying clinical indicators for quality improvement. International Journal for Quality in Health Care, 15, 523-530. doi:10.1093/intqhe/mzg081

[4] Ryan, M., Major, K. and Skâtun, D. (2005) Using discrete choice experiments to go beyond clinical outcomes when evaluating clinical practice. Journal of Evaluation in Clinical Practice, 22, 328-238. doi:10.1111/j.1365-2753.2005.00539.x

[5] Brook, R.H., McGlynn, E.A. and Shekelle, P.G. (2000) Defining and measuring quality of care: A perspective from US researchers. International Journal for Quality in Health Care, 12, 281-295. doi:10.1093/intqhc/12.4.281
[6] Eldar, R. (1999) Quality of care in rehabilitation medicine. International Journal for Quality in Health Care, 11, 7379. doi:10.1093/intqhe/11.1.73

[7] Breemhaar, B., Visser, A.P.H. and Kleijnen, J.G.V.M. (1990) Perceptions and behaviour among elderly hospital patients: Description and explanation of age differences in satisfaction, knowledge, emotions and behaviour. Social Science \& Medicine, 31, 1377-1385. doi:10.1016/0277-9536(90)90076-5

[8] Ross, C.E. and Mirowsky, J. (1984) Socially-desirable response and acquiescence in a cross-cultural survey of mental health. Journal of Health and Social Behavior, 25, 189-197. doi: $10.2307 / 2136668$

[9] Crow, R., Gage, H., Hampson, S. and Hart, J. (2002) The measurement of satisfaction with healthcare: implications for practice from a systematic review of the literature. Health Technology Assess, 6.

[10] Lanscar, E. and Louviere, J. (2008) Conducing discrete choice experiments to inform healthcare decision making: A user's guide. Pharmacoeconomics, 26, 661-677. doi:10.2165/00019053-200826080-00004

[11] Ryan, M. (2004) Discrete choice experiments in health care: NICE should consider using them for patient centred evaluations of technologies. BMJ, 328, 360-361. doi:10.1136/bmj.328.7436.360

[12] Gerard, K. and Ryan, M. (2008) Discrete choice experiments in a nutshell. In: Ryan, M., Gerard, K. and AmayaAmaya, M., Eds., Using Discrete Choice Experiments to Value Health and Health Care, Springer, Dordrecht.

[13] Grøndahl, V.A., Karlsson, I., Hall-Lord, M.L., Appelgren, J. and Wild-Larsson, B. (2011) Quality of care from patients' perspective: Impact of the combination of personrelated and external objective care conditions. Journal of Clinical Nursing, 20, 2540-2551. doi:10.1111/j.1365-2702.2011.03810.x

[14] Street, D. and Burgess, L. (2007) The construction of optimal stated choice experiments: Theory and methods. Wiley, Hoboken. doi:10.1002/9780470148563

[15] Folstein, M.F., Folstein, S.E. and McHugh, P.R. (1975) "Mini Mental State" A practical method for grading the cognitive state of patients for the clinician. Journal of Psychiatric Research, 12, 189-198. doi:10.1016/0022-3956(75)90026-6

[16] Stata Corp. (2009) Stata statistical software: Release 11. College station. StataCorp LP., Texas.

[17] Ryan, M., Watson, V. and Gerard, K. (2008) Practical issues in conducting a discrete choice experiment. In: Ryan, M., Gerard, K. and Amaya-Amaya, M., Eds., Using Discrete Choice Experiments to Value Health and Health Care. Springer, Dordrech.

[18] Lanscar, E and Louviere, J. (2006) Deleting "irrational" responses from discrete choice experiments: A case of investigating or imposing preferences? Health Economics, 15, 797-811. doi:10.1002/hec.1104

[19] Cornwell, J., Levenson, R., Sonola, L. and Poteliakhoff, E. (2012) Continuity of care for older hospital patients: A call for action. The Kings Fund.

[20] Jacelon, C.S. (2004) Older adults and autonomy in acute 
care: Increasing patients' independence and control during hospitalization. Journal of Gerontological Nursing, 30, 29-36.

[21] Lothian, K. and Philp, I. (2001) Maintaining the dignity and autonomy of older people in the healthcare setting. BMJ, 332, 668-670. doi:10.1136/bmj.322.7287.668

[22] Atwal, A., Tattersall, K., Murphy, S., Davenport, N., Craik, C. and Caldwell, K. (2007) Older adults experiences of rehabilitation in acute health care. Scandinavian Journal of Caring Science, 21, 371-378. doi:10.1111/j.1471-6712.2007.00469.x

[23] Lui, M.H.L. and Mackenzie, A.E. (1999) Chinese elderly patients' perceptions of their rehabilitation needs following a stroke. Journal of Advanced Nursing, 30, 391-400. doi:10.1046/j.1365-2648.1999.01087.x

[24] Department of Health and Ageing (2012) E-Health, Australia.

http://www.ehealth.gov.au/internet/ehealth/publishing.nsf/ content/home

[25] Westby, M.D. and Backman, C.L. (2010) Patient and health professional views on rehabilitation practices and outcomes following total hip and knee arthroplasty for osteoarthritis: A focus group study. BMC Health Services Research, 10.

[26] McMurdo, M.E.T., Roberts, H., Parker, S., Wyatt, N., May, H., Goodman, C., et al. (2011) Improving recruitment of older people to research through good practice. Age Ageing, 40, 65. doi:10.1093/ageing/afr115 